\title{
The climate adaptability evaluation of biogas fermentation assisted by solar greenhouse
}

\author{
Xiaolu $\mathrm{Shao}^{1}$, Xing $\mathrm{Su}^{1 *}$, Shaochen $\mathrm{Tian}^{1}$, and Jian $\mathrm{Cai}^{1}$ \\ ${ }^{1}$ School of Mechanical Engineering, Tongji University, 1239 Siping Road, Shanghai 200092, China
}

\begin{abstract}
The production efficiency of biogas digesters is largely restricted by the low environment temperature in winter, for most regions of China. As a feasible means of warming and heat preservation, solar greenhouse has the ability to expand the application scope and service time of biogas in rural China. The evaluation of climate adaptability of solar greenhouse is of great importance and imminent, due to the fact that both solar energy and biomass resources are affected by climate. In this paper, a complete evaluation index system for climate adaptability of biogas fermentation assisted by solar greenhouse was established. The indicators of the evaluation index system were selected by means of frequency analysis and theoretical analysis. The weights of the indicators, including solar radiation, outdoor air temperature, crop yields and human and animal manure, were determined by analytic hierarchy process combined with literature research, and the scoring rules were based on the objective significance of each indicator. The climate adaptability of typical cities in the Yangtze River Delta was evaluated with the evaluation index system. Among the cities, Hefei shows the best comprehensive adaptability, and then is Xuzhou, Shanghai, Nanjing, and the lowest adaptability, Hangzhou. The comprehensive adaptability results of these cities depend not only on the gas production capacity, but also on the biomass resource and solar radiation.
\end{abstract}

\section{Introduction}

At present, China has a huge potential of agricultural waste resources that can be used for biogas. Rural biogas raw materials mainly include crop straw, livestock and poultry excrement, agricultural products processing residues, vegetable residues, rural organic household garbage and so on. It is estimated that the total amount of waste resources available for biogas production is about 1.404 billion tons, including more than 100 million tons of straw, more than 1 billion tons of livestock and poultry waste, and more than 100 million tons of other organic waste. The production potential of biogas is about 122.7 billion cubic meters [1].

In the process of biomass anaerobic fermentation, the biogas fermentation temperature will affect the gas production efficiency [2]. In most of China, the winter is cold for a long time, and the biomass gas production efficiency and raw material decomposition efficiency are low. Solar greenhouse can be used for overall heating of biogas digester, and the greenhouse is easy to build and the cost of construction, operation and maintenance is low. Based on solar greenhouse, the increase of temperature and the stability of temperature change can improve the biogas production and ensure the efficiency of biogas production. Biogas production depends on biomass energy, which varies from region to region with climate, and solar energy used in solar greenhouse is also affected by climate region.

There are many studies [3-8] on biomass energy potential assessment. Olanrewaju et al. [3] made quantitative estimates of the potential of Agricultural waste, forest waste and waste for energy production in Nigeria based on data from the Nigerian Government. Toklu [6] assessed Turkey's biomass energy potential. Huo et al. [7] assessed the comprehensive utilization potential of straw in China in 2015, which is 876 million tons, including 476 million tons of straw fertilizer, 220 million tons of straw feed, 120 million tons of straw energy, and 60 million tons of straw base materials and raw materials. Zhang Beibei [8] estimated the resource amount and energy potential of China's existing agricultural and forestry residues based on the data of 2015 National Statistical Yearbook. Based on biomass

*Corresponding Author: Tel: +862165984243 , Fax: +86 2165983605

E-mail: suxing@tongji.edu.cn 
energy distribution and potential, biogas production estimation in various regions has also been studied. Batzias et al. [9] developed the Animal Energy Potential Database (ABEPE), a GIS based biomass resource assessment application which uses a relational database management system to estimate biogas production from livestock manure.

The evaluation of climate adaptability of solar greenhouse is of great importance and imminent, due to the fact that both solar energy and biomass resources are affected by climate. The adaptability of 31 regions in China was evaluated by comprehensively considering the total amount of resources (viz. livestock and poultry manure, crop straw), competitive utilization approaches (viz. fertilizer, feedstuff, raw material, base material), regional differentiation rule, biogas development foundation, economic level, clean energy demand and other factors in each region [1]. Ren Yulian [10] analyzed the influencing factors of the adaptability of household biogas in rural areas of China, established an evaluation index system for the suitability of household biogas, and conducted a comprehensive evaluation and regional planning for the suitability of household biogas in rural areas of China at present and in the future.

In this paper, a complete evaluation index system for climate adaptability of biogas fermentation assisted by solar greenhouse was established. The process of establishing the evaluation index system of adaptability is divided into the establishment of the index framework, the selection of the index system and the optimization of the index. The commonly used methods of index primary selection are: literature method, theory mining method, expert scoring method and so on. Among them, the literature method, also known as frequency analysis method, is to carry out statistics on the indicators in papers, journals, national published index systems and other indicators related to the research content, rank the indicators according to the number of occurrences, and then determine the selection of indicators according to the number of occurrences.

As for the solar biogas system, this paper obtained the development status of the system through a large number of literature research and field investigation, and determined the main influencing factors of solar capable fermentation through analysis. The indicators of the evaluation index system for climate adaptability of biogas fermentation assisted by solar greenhouse were selected by means of frequency analysis and theoretical analysis. The weights of the indicators, including solar radiation, outdoor air temperature, crop yields and human and animal manure, were determined by analytic hierarchy process combined with literature research, and the scoring rules were based on the objective significance of each indicator. Finally, the climate adaptability of typical cities in the Yangtze River Delta was evaluated with the evaluation index system.

\section{Evaluation method}

\subsection{Evaluation principle}

It is a complex systematic problem to evaluate the climate adaptability of biogas fermentation assisted by solar greenhouse. In order to obtain accurate and referential evaluation results, it is necessary to establish a scientific and objective evaluation index system. Therefore, the following principles should be followed in establishing the evaluation index system for climate adaptability of biogas fermentation assisted by solar greenhouse.

\subsubsection{Objective principle}

When indicators of the evaluation index system are selected, it is necessary to combine with the reality to focus on whether the data source of these factors is objective and reliable and whether the index coverage is comprehensive and reasonable. The variables in the established mathematical and physical equations and the influence of variables on the final result can be analyzed, because the equation is the embodiment of the relationship between things. At the same time, it is necessary to refer to the previous studies to ensure the objectivity of the indicators.

\subsubsection{Systematization principle}

The evaluation index system for climate adaptability of biogas fermentation assisted by solar greenhouse involves a wide range, many related elements and complex relationships. For example, the climatic conditions and raw material conditions of each region have an impact on the evaluation system. Therefore, the selection of indicators should ensure that the indicators complement, coordinate, restrict and link each other.

\subsubsection{Simplicity principle}

The data selected by the indicator should be from reliable and existing sources. If the data source is not reliable, the evaluation result will not be convincing. If a large number of experiments or questionnaires are needed to obtain the data, the labor and time costs are high, which is not conducive to the analysis of the indicator system. Therefore, the selection of indicators should try to ensure that the data is simple and easy to obtain.

\subsubsection{Operability principle}

Operational principle means to ensure the comparability and feasibility of each indicator. Comparability mainly refers to the exact meaning of the evaluation, which makes it easy to compare each city and judge the pros and cons in the comparison. Feasibility mainly means that the setting of indicator should accord with the characteristics and functional requirements of the whole evaluation system.

\subsubsection{Principle of qualitative and quantitative combination}

On the one hand, it is necessary to combine the actual data for quantitative calculation; on the other hand, it is necessary to obtain quantitative weights based on qualitative index system by certain methods. The final index evaluation should be quantitative in order to obtain objective and reasonable evaluation results. 


\subsection{Evaluation indicator}

The production of biogas is mainly affected by environmental leakproofness, ph value, fermentation concentration, carbon - nitrogen ratio and fermentation temperature. The efficient solar heating technology is used to increase the fermentation temperature, so that the biogas system can produce biogas efficiently and meet the needs of residents throughout the year.

Environmental leakproofness, ph value, fermentation concentration and carbon - nitrogen ratio are all controllable factors. Temperature is one of the important factors that influence microbial life activities, and is also an important influencing factor of dynamics.

Fermentation temperature is the key factor to determine gas production, so there are two important outdoor environmental and climate parameters, namely solar radiation and outdoor air temperature, which can be determined as the main climate impact factor. The above factors can be considered as factors that determine the capacity of a biogas digester to produce gas. For a region, the total amount of straw or human and animal excreta that can be used to produce biogas is also a major factor that affects the total amount of gas production in the region.

According to the current situation and characteristics of rural biogas project in China, through systematic analysis and screening, the importance evaluation indicator with typical representative significance was selected as the analysis object, and finally the evaluation index system for climate adaptability of biogas fermentation assisted by solar greenhouse was formed. The index system consists of three levels: target layer, criterion layer and indicator layer. The target layer is the overall target of the index evaluation, namely, the climate applicability of the technology (A). The criterion layer is the classification of factors to be investigated, including climate adaptability (B1) and resource adaptability (B2). The indicator layer is the refinement of the criterion layer, and the indicators are shown in Fig. 1.

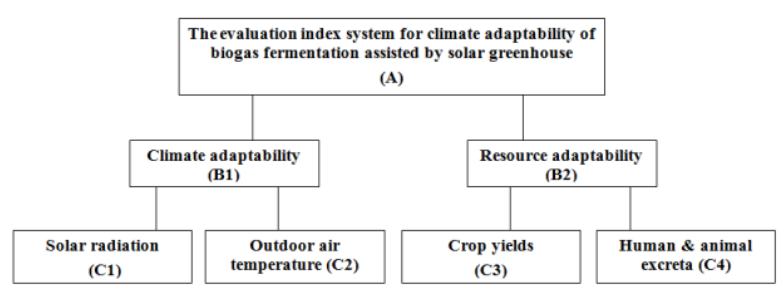

Fig. 1 The evaluation index system

Here $\mathrm{C} 1$ refers to the average annual sunshine duration. Sunshine duration refers to the actual time in hours that the sun shines directly on the ground between sunrise and sunset every day. Sunshine duration is not only restricted by the length of day and night, but also affected by weather conditions such as cloud, rain and ground cover. $\mathrm{C} 2$ refers to the average annual temperature. The average annual temperature refers to the average temperature of many years. The average annual temperature and average annual sunshine duration are generally referred to as averages over many years. C3 refers to the crop yields in a given region, in units of tons, etc. C4 refers to rural population and the number of livestock and poultry kept at the end of the year. Rural population refers to the number of permanent residents in a rural household. The number of livestock and poultry kept at the end of the year generally refers to the total number of livestock and poultry alive in a certain area.

\subsection{Evaluation indicator weight}

The climatic factors include solar radiation and outdoor air temperature, both of which are included in the calculation formula of gas production capacity. There is no simple linear relationship between the two indicators and the gas production capacity. However, in order to determine the weight, mathematical tools can be used to directly evaluate the weight of the two influencing factors by means of multinomial fitting. The simulation result of a certain place is used here as the fitting original data. The solar radiation and outdoor air temperature are set as the independent variable $\mathrm{x} 1, \mathrm{x} 2$ respectively. The gas production per pool capacity is $\mathrm{y}$. Each quantity needs to be normalized separately, otherwise its dimension will adversely affect the fitting result.

Since the above indicators are all positive indicators, the entropy normalization method is adopted to process the original data, as shown in equation (1) below:

$$
x_{i}{ }^{\prime}=\frac{x_{i}}{x_{\max }}
$$

Here $i$ is 1 or 2 .

Fig. 2 and formula (2) are obtained after the first degree bivariate polynomial fitting.

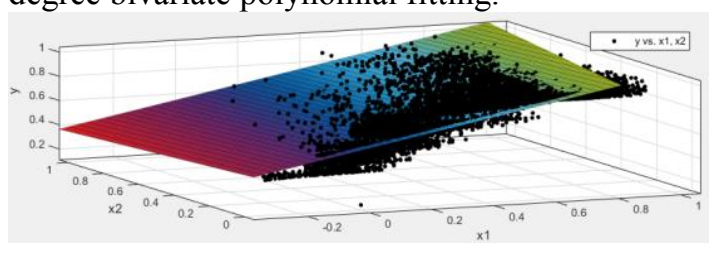

Fig. 2 Multinomial fitting image of gas production

$$
\mathrm{y}=0.6398-0.08762 \mathrm{x}_{1}+0.4919 \mathrm{x}_{2}
$$

The R-squared of the above formula is 0.7458 , which is not an ideal value, but the coefficients of the two independent variables have certain reference value for determining the weight of their impacts on climate. The coefficients of $\mathrm{x} 1$ and $\mathrm{x} 2$ in the above equation are normalized, namely, their influence weights, as shown in the Table 1.

Table 1 Weight distribution of climate indicators

\begin{tabular}{|c|c|}
\hline Indicator & $\begin{array}{c}\text { Weights within the } \\
\text { hierarchy }\end{array}$ \\
\hline Solar radiation & 0.15 \\
\hline Outdoor air temperature & 0.85 \\
\hline
\end{tabular}

As for the weight of resource factors, crop yields and human and animal excreta have their respective gas 
production rates. The contribution of corresponding factors to biogas production can be used as a reference to determine the influence weight. The gas production ratios of different crop and animal excreta are shown in the Table 2. There are many kinds of biogas fermentation raw materials, and the gas production ratios of some major resources are listed in Table 2.

Table 2 Gas producing factors of various raw materials

\begin{tabular}{|c|c|c|c|c|c|}
\hline \multirow[t]{2}{*}{$\begin{array}{c}\text { Types } \\
\text { of } \\
\text { straw }\end{array}$} & \multicolumn{2}{|c|}{$\begin{array}{c}\text { Theoretical gas } \\
\text { production / } \\
\left(\mathrm{m}^{3} / \mathrm{kg}\right)\end{array}$} & \multirow[t]{2}{*}{$\begin{array}{l}\text { Types } \\
\text { of } \\
\text { excreta }\end{array}$} & \multicolumn{2}{|c|}{$\begin{array}{l}\text { Theoretical gas } \\
\text { production / } \\
\left(\mathrm{m}^{3} / \mathrm{kg}\right)\end{array}$} \\
\hline & biogas & methane & & biogas & methane \\
\hline $\begin{array}{l}\text { Corn } \\
\text { straw }\end{array}$ & 0.5984 & 0.3109 & $\begin{array}{l}\text { Pig } \\
\text { dung }\end{array}$ & 0.5146 & 0.2145 \\
\hline $\begin{array}{l}\text { Wheat } \\
\text { straw }\end{array}$ & 0.5426 & 0.2756 & $\begin{array}{l}\text { Cow } \\
\text { dung }\end{array}$ & 0.3813 & 0.2062 \\
\hline $\begin{array}{l}\text { Rice } \\
\text { straw }\end{array}$ & 0.5291 & 0.2781 & $\begin{array}{c}\text { Chicken } \\
\text { dung }\end{array}$ & 0.5047 & 0.2645 \\
\hline
\end{tabular}

It can be seen from Table 2 above that the theoretical gas production of crop straw is generally higher than that of human and animal excreta. The supply of crop straw is more stable, but its total amount is less than the amount of feces. Referring to the analytic hierarchy process results of biogas adaptability evaluation studies of other researchers, as shown in the Table 3, the weight of crop yield was determined as 0.47 , and the weight of human and animal excreta as 0.53 , namely by making an arithmetic average of the literature results for both values.

Table 3 Weights of crop yields and human and animal excreta in different studies

\begin{tabular}{|l|c|c|}
\hline \multicolumn{1}{|c|}{ Reference } & $\begin{array}{c}\text { Weight } \\
\text { of crop } \\
\text { yields }\end{array}$ & $\begin{array}{c}\text { Weight } \\
\text { of human } \\
\text { and } \\
\text { animal } \\
\text { excreta }\end{array}$ \\
\hline $\begin{array}{l}\text { Fujian comprehensive utilization of } \\
\text { biogas technology choice and } \\
\text { suitability of evaluation [11] }\end{array}$ & 0.52 & 0.48 \\
\hline $\begin{array}{l}\text { Evaluation of regional adaptability of } \\
\text { new household biogas - A case } \\
\text { study of Jiangsu province [12] }\end{array}$ & 0.5 & 0.5 \\
\hline $\begin{array}{l}\text { Assessment of suitability of the rural } \\
\text { household biogas system in the } \\
\text { Yellow River Basin based on a } \\
\text { questionnaire method [13] }\end{array}$ & 0.35 & 0.65 \\
\hline $\begin{array}{l}\text { Regional suitability evaluation of } \\
\text { China rural domestic biogas project } \\
\text { [14] }\end{array}$ & 0.5 & 0.5 \\
\hline This paper & 0.47 & 0.53 \\
\hline
\end{tabular}

The previous analysis has determined the weight distribution relationship between the factors below the climate and resource level, while the weight of climate and resource level itself still needs to be determined. The weights of climate and resource are determined in many biogas regional adaptability evaluation studies, so the method of literature research is adopted here to determine their weights. The weights obtained from literature research are listed as follows.
Table 4 Weights of climate and resource in different studies

\begin{tabular}{|l|c|c|}
\hline \multicolumn{1}{|c|}{ Reference } & $\begin{array}{c}\text { Weight } \\
\text { of } \\
\text { climate }\end{array}$ & $\begin{array}{c}\text { Weight } \\
\text { of } \\
\text { resource }\end{array}$ \\
\hline $\begin{array}{l}\text { Evaluation of regional adaptability } \\
\text { of new household biogas_- A } \\
\text { case study of Jiangsu province[12] }\end{array}$ & 0.55 & 0.45 \\
\hline $\begin{array}{l}\text { Assessment of suitability of the } \\
\text { rural household biogas system in } \\
\text { the Yellow River Basin based on a } \\
\text { questionnaire method [13] }\end{array}$ & 0.83 & 0.17 \\
\hline $\begin{array}{l}\text { Regional suitability evaluation of } \\
\text { China rural domestic biogas project } \\
\text { [14] }\end{array}$ & 0.70 & 0.30 \\
\hline $\begin{array}{l}\text { Household biogas use in China: A } \\
\text { study of region suitability and } \\
\text { sustainability [15] }\end{array}$ & 0.74 & 0.26 \\
\hline $\begin{array}{l}\text { Research on index system and } \\
\text { classification standard for } \\
\text { household biogas region suitability } \\
\text { evaluation [16] }\end{array}$ & 0.67 & 0.33 \\
\hline This paper & 0.70 & 0.30 \\
\hline
\end{tabular}

It can be clearly seen from the above Table 4 that the weight of climate is significantly higher than that of resource, and most of them are around 0.7 . Therefore, in this study, the weight of climate is set as 0.7 , and the weight of resource is set as 0.3 , namely by making an arithmetic average of the literature results for both values.

After the weights of different levels are determined through discussion, calculation and investigation, the weights of each indicator can be obtained as shown in Table 5, which can be used as the basis for subsequent evaluation model.

Table 5 Evaluation index system for climate adaptability of biogas fermentation assisted by solar greenhouse

\begin{tabular}{|c|c|c|c|c|}
\hline $\begin{array}{c}\text { The target } \\
\text { layer }\end{array}$ & $\begin{array}{c}\text { The } \\
\text { criterion } \\
\text { layer }\end{array}$ & $\begin{array}{c}\text { Weigh } \\
\mathrm{t}\end{array}$ & $\begin{array}{c}\text { The } \\
\text { indicator } \\
\text { layer }\end{array}$ & $\begin{array}{c}\text { Weigh } \\
\mathrm{t}\end{array}$ \\
\hline $\begin{array}{c}\text { Evaluation } \\
\text { index } \\
\text { system for } \\
\text { climate } \\
\text { adaptability } \\
\text { of biogas } \\
\text { fermentatio } \\
\text { n assisted } \\
\text { by solar } \\
\text { greenhouse }\end{array}$ & $\begin{array}{c}\text { Resourc } \\
\mathrm{e}\end{array}$ & 0.30 & $\begin{array}{c}\text { Colar } \\
\text { radiation }\end{array}$ & 0.105 \\
\cline { 4 - 5 } & & $\begin{array}{c}\text { Outdoor air } \\
\text { temperatur } \\
\text { e }\end{array}$ & 0.595 \\
\cline { 4 - 5 } & & $\begin{array}{c}\text { Human and } \\
\text { animal } \\
\text { excreta }\end{array}$ & 0.159 \\
\hline
\end{tabular}

\subsection{Evaluation scoring rule}

After determining the weight of each indicator, the score rule of each indicator is formulated, and the total score of each region is calculated based on the weight for comparison.

\subsubsection{Solar radiation scoring rules}

Solar radiation indicator is a positive indicator for the biogas system, and the more abundant the solar energy 
resources are, the more favorable the biogas production will be. In order to compare different regions, the region with the maximum solar radiation can be taken as the benchmark, and the score is defined as 100 . The formula is as follows.

$$
S_{i}=\frac{X_{i}-X_{\text {min }}}{X_{\text {max }}-X_{\text {min }}} \times 100
$$

Here $S_{i}$ is the score of solar radiation in a certain region. $X_{i}$ is solar radiation in a certain region. $X_{\max }$ is the maximum solar radiation of all the regions to be compared. $X_{\min }$ is the minimum solar radiation of all the regions to be compared.

\subsubsection{Outdoor air temperature scoring rules}

The outdoor air temperature indicator is not a simple positive indicator, and the evaluation score cannot be simply given according to the air temperature. The gas production rate of biogas is relatively high with higher outdoor air temperature. However, when the outdoor air temperature is lower than $10^{\circ} \mathrm{C}$, it will be difficult to produce biogas. Therefore, the monthly temperature distribution should be considered in this score. One simple way is to give a score according to the annual average temperature of a certain region according to the solar radiation scoring rules, and then calculate the proportion of the months whose monthly average temperature is higher than $10^{\circ} \mathrm{C}$ in the whole year, then revise the previous score, and finally get the outdoor air temperature score. For biogas projects with greenhouse warming technologies, the influence of outdoor air temperature on gas production will be weakened. In this case, it can be assumed that the evaluated region has the full mark of outdoor air temperature indicator, which can be modified by multiplying the score by the annual share of the month whose monthly air temperature is higher than $10^{\circ} \mathrm{C}$. The result is the score of outdoor air temperature indicator.

\subsubsection{Scoring rules for crop resources.}

Crop yields indicator is a positive indicator, and higher crop yield will provide more biogas. Scores are obtained according to the solar radiation scoring rules.

\subsubsection{Scoring rules for human and animal excreta resources}

Human and animal excreta indicator is positive indicator. Scores are obtained according to the solar radiation scoring rules.

\section{Results and discussion}

Two aspects should be considered for the regional division of climate adaptability of biogas fermentation assisted by solar greenhouse: raw material resources and theoretical gas production capacity, of which the gas production capacity in this chapter is only calculated according to the temperature.
Fermentation raw material resources are mainly divided into straw biomass resources and livestock and poultry manure biomass resources. The amount of raw material resources of major cities in the Yangtze river delta is calculated according to the statistical yearbook of each region as shown in Fig. 3. It can be seen that Xuzhou has the most total raw material resources in each region, followed by Hefei, Shanghai, Hangzhou, Nanjing and Wenzhou. The total amount of fermentation raw material resources varies greatly among cities, and the raw material resources are relatively less in Hangzhou and Nanjing. There are great differences in biomass resources among different provinces in the Yangtze River Delta, which is mainly due to the different development emphases and different agricultural total product of provinces. According to the resources, Xuzhou, Hefei and Shanghai are more suitable for the promotion of biogas technology.

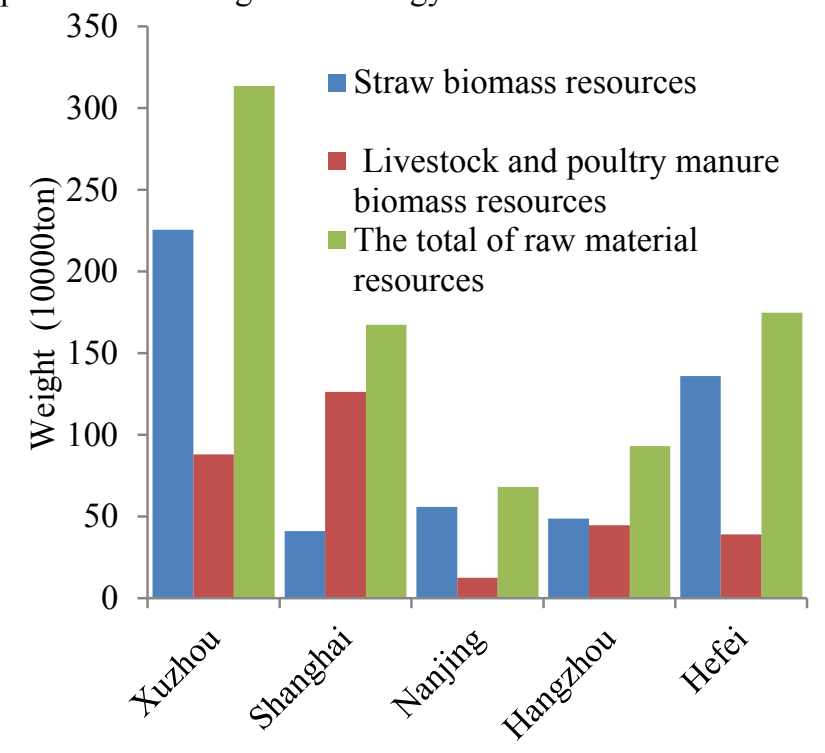

Fig. 3 Comparison of fermentation raw material resources

\subsection{Theoretical gas production capacity}

The gas production capacity of biogas can be obtained by daily air temperature in a year, and the annual biogas output can be estimated. The results are shown in Fig. 4.

\subsection{Analysis of raw material resources}




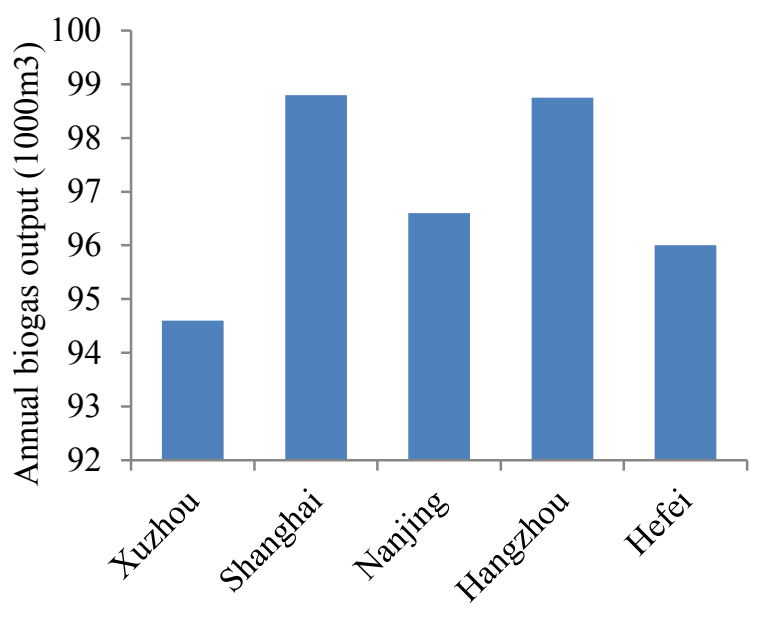

Fig. 4 Comparison of theoretical gas production capacity

The results were similar to the annual average temperature ranking of cities. The theoretical gas production only considers the influence of daily outdoor air temperature on gas production, ignoring solar radiation and other factors. It can be seen from Figure 4 that cities in hot-summer and cold-winter regions, such as Shanghai and Hangzhou, have more environmental advantages in biogas production than Xuzhou in cold region. For biogas projects with greenhouse warming technologies, the influence of outdoor air temperature on gas production will be weakened. Assisted by solar greenhouse, the actual gas production of cities such as Hefei with more total raw material resources and solar radiation but low outdoor air temperature may be improved.

\subsection{Classification criteria for climate adaptation}

For the biogas fermentation system assisted by solar greenhouse, regions with comprehensive evaluation scores greater than 60 are suitable areas in the comparison cities. The area with the comprehensive evaluation score between 60 and 55 is the sub-suitable area in the comparison city. The area with the comprehensive evaluation score between 50 and 55 is the common area in the comparison city. Areas with comprehensive evaluation score less than 50 are not recommended for application, as shown in Table 6 .

Table 6 Climate adaptability grading standards for biogas fermentation system assisted by solar greenhouse

\begin{tabular}{|c|c|c|c|c|}
\hline $\begin{array}{c}\text { Suitable } \\
\text { division }\end{array}$ & $\begin{array}{c}\text { Suitabl } \\
\text { e areas } \\
\text { ( I ) }\end{array}$ & $\begin{array}{c}\text { Sub- } \\
\text { suitabl } \\
\text { e area } \\
\text { (II })\end{array}$ & $\begin{array}{c}\text { Commo } \\
\text { n area } \\
\text { (III) }\end{array}$ & $\begin{array}{c}\text { Unrecommend } \\
\text { ed area (IV) }\end{array}$ \\
\hline $\begin{array}{c}\text { Climate } \\
\text { adaptabilit } \\
\text { y grading } \\
\text { standards }\end{array}$ & $>60$ & $\begin{array}{c}60 \sim \\
55\end{array}$ & $55 \sim 50$ & $<50$ \\
\hline
\end{tabular}

3.4 Evaluation of climate adaptability of biogas fermentation assisted by solar greenhouse in typical cities of The Yangtze River Delta
The climate adaptability of biogas fermentation assisted by solar greenhouse of typical cities in the Yangtze River Delta was evaluated with the evaluation index system. In this paper, the score of each indicator and the total evaluation score according to the weight are calculated as shown in Table 7.

Table 7 The score of each indicator and the total evaluation score of typical cities

\begin{tabular}{|c|c|c|c|c|c|}
\hline City & $\begin{array}{c}\text { Shang } \\
\text { hai }\end{array}$ & $\begin{array}{c}\text { Nanjin } \\
\mathrm{g}\end{array}$ & $\begin{array}{c}\text { Hangzh } \\
\text { ou }\end{array}$ & Hefei & Xuzhou \\
\hline $\begin{array}{c}\text { Score of } \\
\text { solar } \\
\text { radiatio } \\
\text { n }\end{array}$ & 49.08 & 43.51 & 8.94 & 39.43 & 13.2 \\
\hline $\begin{array}{c}\text { Score of } \\
\text { outdoor } \\
\text { air } \\
\text { temperat } \\
\text { ure }\end{array}$ & 75 & 75 & 75 & 75 & 66.67 \\
\hline $\begin{array}{c}\text { Score of } \\
\text { crop } \\
\text { yield }\end{array}$ & 15.6 & 16.21 & 8.88 & 42.88 & 63.35 \\
\hline $\begin{array}{c}\text { Score of } \\
\text { human } \\
\text { and } \\
\text { animal } \\
\text { excreta }\end{array}$ & 14.41 & 3.1 & 13.52 & 14.82 & 36.35 \\
\hline $\begin{array}{c}\text { Total } \\
\text { evaluati } \\
\text { on score }\end{array}$ & 54.27 & 51.97 & 48.97 & 57.17 & 55.77 \\
\hline $\begin{array}{c}\text { Evaluati } \\
\text { on }\end{array}$ & III & III & IV & II & II \\
\hline
\end{tabular}

Among the cities, Hefei shows the best comprehensive adaptability, and then is Xuzhou, Shanghai, Nanjing, and the lowest adaptability, Hangzhou. According to the regional adaptability classification standard, Hefei and Xuzhou belong to the sub-suitable area, while Shanghai and Nanjing belong to the common area and Hangzhou belongs to the unrecommended area. For biogas projects with greenhouse warming technologies, the influence of outdoor air temperature on gas production will be weakened. Assisted by solar greenhouse, the climate adaptability of cities such as Xuzhou with most total raw material resources but low outdoor air temperature may be improved.

\section{Conclusion}

In this paper, a complete evaluation index system for climate adaptability of biogas fermentation assisted by solar greenhouse was established. The indicators of the evaluation index system were selected by means of frequency analysis and theoretical analysis. The weights of the indicators, including solar radiation, outdoor air temperature, crop yields and human and animal manure, are $0.105,0.595,0.141$ and 0.159 respectively.

The climate adaptability of typical cities in the Yangtze River Delta was evaluated with the evaluation index system. Among the cities, Hefei shows the best 
comprehensive adaptability, and then is Xuzhou, Shanghai, Nanjing, and the lowest adaptability, Hangzhou. The comprehensive adaptability results of these cities depend not only on the gas production capacity, but also on the biomass resource and solar radiation.

There is a gap between the statistical data of resource quantity mentioned in this paper and the actual amount of recyclable resources. The collection of human and animal excreta is more difficult than the collection of crop straw resources. In the process of practical application evaluation, it is suggested to carry out a field investigation on the collection of local resources for biogas production and revise the theoretical resource quantity, so as to obtain a more practical evaluation result.

This research has been supported by the China National Key R\&D Program during the 13th Five-year Plan Period under Grant No. 2018YFD1100700.

\section{Reference}

[1] "National rural biogas development "13th Five Year Plan"," Chinese Industry \& Economy, no. 4, pp. 73-75, 2017.

[2] Z. Xu, China biogas technology. Beijing: Agricultural Press of China, 1981.

[3] F. O. Olanrewaju, G. E. Andrews, H. Li, and H. N. Phylaktou, "Bioenergy potential in Nigeria," Chemical Engineering Transactions, Article vol. 74, pp. 61-66, 2019.

[4] M. F. H. Masum, K. Sahoo, and P. Dwivedi, "Ascertaining the Trajectory of Wood-Based Bioenergy Development in the United States Based on Current Economic, Social, and Environmental Constructs," in Annual Review of Resource Economics, Vol 11, vol. 11, G. C. Rausser and D. Zilberman, Eds. (Annual Review of Resource Economics, 2019, pp. 169193.

[5] F. N. Mancini, J. Milano, J. G. de Araujo, K. T. Iastrenski, N. S. Silveira, and R. C. Pertile, "Energy Potential of Animal Waste in the State of Parana (Brazil)," Brazilian Archives of Biology and Technology, vol. 62, 2019, Art. no. e19190009.

[6] E. Toklu, "Biomass energy potential and utilization in Turkey," Renewable Energy, Article vol. 107, pp. 235-244, 2017.

[7] L. Huo, L. Zhao, H. Meng, and Z. Yao, "Study on straw multi-use potential in China," Nongye Gongcheng Xuebao/Transactions of the Chinese Society of Agricultural Engineering, Article vol. 35, no. 13, pp. 218-224, 2019.

[8] B. Zhang, "Assessment of raw material supply capability and energy potential of biomass resources in China," Doctor, China Agricultural University, 2018.
[9] F. A. Batzias, D. K. Sidiras, and E. K. Spyrou, "Evaluating livestock manures for biogas production: a GIS based method," Renewable Energy, vol. 30, no. 8, pp. 1161-1176, Jul 2005.

[10] Y. Ren, "Research on planning of household biogas regional suitability in rural area of China," Master, Harbin Institute of Technology, 2017.

[11] M. Gao, "Fujian comprehensive utilization of biogas technology choice and suitability of evaluation," Master, Fujian Agriculture and Forest University 2010.

[12] Y. Zhang, C. Zhu, and E. Zhao, "Evaluation of regional adaptability of new household biogas_- A case study of Jiangsu province," Jiangsu Agricultural Sciences, vol. 42, no. 05, pp. 353-355, 2014.

[13] H. Li, "Assessment of suitability of the rural household biogas system in the Yellow River Basin based on a questionnaire method," Master, Cninese Academy of Agricultural Sciences, 2011.

[14] G. Liu and T. You, "Regional suitability evaluation of China rural domestic biogas project," Journal of Anhui Agricultural Sciences, vol. 40, no. 28, pp. 14128-14131, 2012.

[15] Y. Chen, "Household biogas use in China: A study of region suitability and sustainability," Doctor, Northwest A \& F University, 2011.

[16] Y. Chen, G. Yang, Y. Feng, F. Bao, and G. Ren, "Research on index system and classification standard for household biogas region suitability evaluation," Agricultural Research in the Arid Areas, no. 05, pp. 228233, 2008. 